\title{
SELECTION OF BASIC COMPETENCY FOR CANDIDATE CIVIL SERVANTS IN INDONESIA 2018: PROBLEMS AND RECOMMENDATIONS
}

\author{
Wisber Wiryanto \\ Pusat Inovasi Administrasi Negara, Lembaga Administrasi Negara, Indonesia \\ Email: wisberwiryanto@yahoo.com
}

\begin{abstract}
Basic Competency Selection Candidates for Civil Servants in 2018 have the following problems: First, the passing-grade information of SKD-CPNS which was stated based on the regulation of MENPANRB No. 37/2018 but in fact not everything is based on that regulation. The reasons are: (1) SKD passing-grade score is the minimum score that must be fulfilled by each CPNS selection participant, not exceeding the passing grade score; (2) SKD-CPNS passing grade scores of athletes who excel are not stated in the SKD-CPNS passing-grade information, even though they should be determined, the lowest score of the CPNS selection participants who excel is the passing grade of SKD results; (3) Scores of the General Intelligence Test (TIU) formation of specialist doctors and pilot instructors who are required to work with very low error standards but are equated with TIU scores of general paths of at least 80. This means that the TIU scores below the cumlaude and diaspora lines are at least 85 . Second, the graduation of the 2018 SKD-CPNS participants nationally is very small, only 3\%. Most participants did not meet the passing grade score of 143 Personal Characteristics Test (TKP) which was too high, in contrast to the score of Nationality Insights Test (TWK) 75 and lower TIU 80. The SKD-CPNS issue requires recommendations because after a week of selection, the government agency has not yet announced the graduation of SKD-CPNS participants. Need to review SKD-CPNS passing-grade information so that it is in accordance with the regulation of MENPANRB No. 37/2018. The TKP passing grade score is too high (143), when compared with TWK scores (75) and TIU (80) which are much lower. Therefore the TKP score should be lowered and the determination of graduation based on the best ranking needs to be applied.
\end{abstract}

Keywords: Selection of Basic Competencies, Candidate Civil Servants

\section{PENDAHULUAN}

Manajemen sumber daya manusia merupakan aspek penting dalam organisasi baik di sektor publik maupun di sektor swasta. Sedarmayanti (2013) menyatakan pemberdayaan SDM aparatur dilaksanakan dengan memperhatikan rekrutmen sesuai prosedur, termasuk perlu memenuhi persyaratan jabatan sesuai peringkat.

Pemerintah juga mengamanatkan arti pentingnya pemberdayaan SDM aparatur dengan menerbitkan Peraturan Pemerintah Nomor 11/2017 tentang Manajemen PNS. Kebijakan penataan SDM aparatur dilaksanakan dengan memperhatikan penerapan sistem merit. Manajemen PNS dimulai dari fungsi rekrutmen dengan melakukan tahapan seleksi terhadap calon pegawai negeri sipil.

Seleksi calon pegawai negeri sipil di Indonesia tahun 2018 diawali dengan proses seleksi administratif dan selanjutnya dilakukan melalui tes. Tes diawali dengan seleksi kompetensi dasar calon pegawai negeri sipil (SKD-CPNS). Kebijakan pemerintah dalam hal rekrutmen CPNS Tahun 2018, khususnya ketentuan SKD-CPNS 2018 mengacu pada 2 (dua) peraturan sebagai berikut:

Pertama, Peraturan MENPANRB Nomor 36/2008 tentang Kriteria Penetapan Kebutuhan dan Pelaksanaan Seleksi CPNS Tahun 2018. Ketentuan pelaksanaan seleksi CPNS 2018, antara lain: 
(1) Menggunakan metode Computer Assisted Test (CAT). CAT adalah suatu metode seleksi/tes dengan menggunakan komputer;

(2) Menggunakan penilaian Passing Grade adalah nilai ambang batas kelulusan SKD. Untuk pengadaan CPNS 2018, nilai ambang batas kelulusan akan ditetapkan dalam Peraturan MENPANRB tersendiri (Lampiran Peraturan MENPANRB No. 36/2018 huruf B Angka $13)$

(3) Tujuan pengadaan CPNS, antara lain mewujudkan sistem seleksi CPNS yang kompetitif, adil, obyektif, transparan, tidak dipungut biaya, bersih dari praktik KKN serta bebas dari intervensi politik;

(4) Prinsip pengadaan CPNS (Lampiran Peraturan MENPANRB Nomor 36/2018 Huruf G angka 3) mencakup: (a) kompetitif, (b) adil, (c) obyektif, (d) transparan, (e) bersih dari praktik KKN, dan (f) tidak dipungut biaya; (5) Memenuhi nilai ambang batas serta kelulusan (passing grade) peringkat terbaik (Lampiran Peraturan MENPANRB Nomor 36/2018 huruf J Angka 2 butir d).

(5) Pengumuman hasil/kelulusan SKD ditetapkan dengan Keputusan Ketua Panitia Seleksi Instansi dan diumumkan oleh masing-masing instansi berdasarkan hasil SKD.

Kedua, Peraturan MENPANRB Nomor 37/2018 tentang Nilai Ambang Batas SKD-CPNS 2018. Ketentuan nilai ambang batas SKD-CPNS 2018, yang mencakup: (1) Tes Karakteristik Pribadi (TKP); (2) Tes Intelegensia Umum (TIU); dan (3) Tes Wawasan Kebangsaan (TWK), sebagaimana disajikan dalam tabel 1 .

Dalam pelaksanaan seleksi CPNS 2018 dijumpai banyak permasalahan yang memerlukan solusi. Oleh karena itu, diperlukan pembatasan. Penelitian ini tidak tidak termasuk seleksi administrasi yang dilakukan sebelumnya. Dalam hal ini, kendala pendaftaran CPNS 2018 antara lain: (1) update kartu tanda penduduk; (2) ijazah pelamar tidak sesuai kualifikasi pendidikan yang dipersyaratkan; dan (3) luput memenuhi kelengkapan dokumen syarat keikutsertaan proses seleksi (liputan6.com). Di samping itu, penelitian ini tidak termasuk seleksi kompetensi bidang yang merupakan tes terakhir.

Dengan demikian, penelitian ini dilakukan dengan rumusan masalah, apa masalah SKDCPNS 2018? Tujuan penelitian ini untuk mengetahui masalah SKD-CPNS 2018 dan untuk dapat memberikan solusi berupa saran/rekomendasi.

\section{METODE PENELITIAN}

Kajian Seleksi Kompetensi Dasar Calon Pegawai Negeri Sipil di Indonesia tahun 2018, dilakukan dengan menggunakan metode survei. Sampel penelitian ini adalah peserta SKDCPNS, lokasi di Jakarta. Penelitian ini dilaksanakan pada akhir tahun 2018. Melalui purposive sampling diambil sampel berukuran kecil. Kemudian, data sekunder dikumpulkan, dan analisis deskriptif kualitatif dilakukan untuk menarik kesimpulan.

\section{HASIL DAN PEMBAHASAN}

Hasil kajian SKD-CPNS 2018 menemukan hal-hal sebagai berikut: (1) permasalahan informasi passing grade SKD-CPNS 2018; (2) Permasalahan kesulitan peserta untuk memenuhi nilai ambang batas kelulusan SKD-CPNS 2018 baik peserta formasi umum, maupun formasi cumlaude.

Pertama, Permasalahan informasi passing grade SKD-CPNS 2018 (lihat tabel 1). Tabel 1 tersebut, merupakan salinan ulang informasi sedemikian rupa dari lembaran kertas yang ditempel di papan pengumuman laporan hasil CAT: SKD-CPNS 2018 di tempat pelaksanaan seleksi di Jakarta, 5 November 2018. Isinya, informasi dan keterangan nilai ambang batas 
SKD-CPNS 2018. Namun, apabila informasi tersebut dianalisis maka ditemukan sejumlah permasalahan SKD-CPNS 2018.

Tabel 1. Passing Grade SKD-CPNS 2018

\begin{tabular}{|l|c|c|c|c|}
\hline & TWK & TIU & TKP & Nilai Kumulatif \\
\hline 1. Jalur Umum & 75 & 80 & 143 & - \\
\hline 2. Cumlaude \& Diaspora & - & Paling sedikit 85 & - & Paling sedikit 298 \\
\hline $\begin{array}{l}\text { 3. Dokter Spesialis \& instruktur } \\
\text { Penerbang }\end{array}$ & - & 80 & - & Paling sedikit 298 \\
\hline $\begin{array}{l}\text { 4. Petugas ukur, Rescuer, Anak Buah } \\
\text { Kapal, Pengamat Gunung Api, } \\
\text { Penjaga Mercusuar, Pelatih/Pawang } \\
\text { Hewan \& Penjaga Tahanan }\end{array}$ & - & Paling sedikit 70 & - & Paling sedikit 260 \\
\hline 5. Penyandang disabilitas & - & Paling sedikit 70 & - & Paling sedikit 260 \\
\hline 6. Putra-putri Papua \& Papua Barat & - & Paling sedikit 60 & - & Paling sedikit 260 \\
\hline $\begin{array}{l}\text { 7. Tenaga Guru \& Medis/Paramedis } \\
\text { dari Eks Honorer Kategori II }\end{array}$ & - & Paling sedikit 60 & - & Paling sedikit 260 \\
\hline $\begin{array}{l}\text { 8. Olahragawan Berprestasi } \\
\text { Olarasi }\end{array}$ & - & - & - & - \\
\hline
\end{tabular}

Sumber: Peraturan MENPANRB No.37/2018 tentang Nilai Ambang Batas SKD Pengadaan CPNS Tahun 2018.

Keterangan: Untuk dapat mengikuti seleksi lanjutan pada rekrutmen CPNS Tahun 2018, peserta Seleksi Kompetensi Dasar (SKD) harus melampaui nilai ambang batas (passing grade).

Kedua, Permasalahan kesulitan peserta untuk memenuhi nilai ambang batas kelulusan SKD-CPNS 2018 baik peserta formasi umum, maupun formasi cumlaude. Permasalahan SKD-CPNS 2018 membutuhkan solusi segera karena hingga pelaksanaan seleksi telah berjalan 1 (satu) minggu, instansi pemerintah yang melaksanakan SKD-CPNS 2018 belum mengumumkan kelulusan peserta SKD-CPNS 2018.

Secara nasional ternyata peserta yang memenuhi nilai ambang batas kelulusan sangat kecil. BKN menyatakan, dari sekitar 2,7 juta peserta, baru 3\% yang lulus tahap SKD-CPNS 2018 (detik.com). Contoh di daerah, Gubernur Maluku Kecewa Peserta Tes CPNS Tahap Pertama yang lolos hanya 8 orang (Kompas.com). Dengan demikian, kelulusan peserta tahap SKD-CPNS 2018 secara nasional sangat kecil hanya mencapai $3 \%$.

Diskusi permasalahan SKD-CPNS 2018 difokuskan pada dua penyebab permasalahan sebagai berikut: Pertama, Permasalahan terkait informasi yang ditempelkan pada papan pengumuman laporan hasil CAT: SKD-CPNS 2018 di Jakarta (lihat tabel 1), antara lain:

(1) Informasi tersebut dinyatakan berdasarkan Peraturan MENPANRB No. 37/2018, tapi isinya ternyata tidak sepenuhnya didasarkan Peraturan MENPANRB.

(2) Informasi pada keterangan tabel 1 tersebut, tidak sesuai dengan Peraturan MENPANRB No. 37/2018 (pasal 1) yang menyatakan "nilai ambang batas SKD adalah nilai minimal yang harus dipenuhi oleh setiap peserta seleksi CPNS". Jadi, tidak benar jika harus melampaui nilai ambang batas. Oleh karena itu, seharusnya yang dicantumkan dalam keterangan tersebut, untuk dapat mengikuti seleksi lanjutan pada rekrutmen CPNS 2018, maka peserta SKD-CPNS harus mencapai nilai ambang batas SKD minimal/paling sedikit yang ditetapkan. Nilai ambang batas SKD adalah nilai minimal yang harus dipenuhi oleh setiap peserta seleksi CPNS bukan melampaui nilai ambang batas. 
(3) Nilai ambang batas SKD-CPNS 2018 olahragawan berprestasi tidak dicantumkan, sehingga tidak diketahui nilai ambang batas SKD-CPNS olahragawan berprestasi. Seharusnya informasi tersebut (lihat tabel 1) mengacu pada Peraturan MENPANRB Nomor 37/2018 (Pasal 5 huruf e) yang menyatakan, "nilai terendah dari peserta seleksi CPNS Olahragawan Berprestasi Internasional merupakan nilai ambang batas hasil SKD." Dengan kata lain, nilai ambang batas mereka adalah nilai ambang batas SKD-CPNS 2018 (Peraturan MENPANRB Nomor 37/2018 Pasal 3) yaitu: (a) TWK = 75; TIU = 80; dan $\mathrm{TKP}=143$.

(4) Nilai TIU formasi dokter spesialis \& instruktur penerbang disamakan dengan jalur umum yaitu 80. Adalah tidak adil karena dokter spesialis dan instruktur penerbang harus melaksanakan tugas dengan standar error yang sangat rendah. Sebaiknya, nilai TIU mereka paling sedikit 85 sama dengan nilai Cumlaude \& Diaspora. Kalaupun mereka ingin diberikan kebijakan afirmatif maka mereka dibebaskan saja dalam test bahasa Inggris nantinya. Karena dokter spesialis dan instruktur penerbang mempunyai kompetensi bahasa Inggris yang baik.

Kedua, hasil SKD-CPNS 2018 menunjukkan kesulitan peserta untuk memenuhi nilai ambang batas kelulusan. Hal ini dapat dilihat pada laporan hasil CAT: SKD-CPNS 2018 baik pada formasi umum maupun cumlaude. Contoh mengenai hal ini disajikan pada tabel 2 dan 3 di bawah ini.

Tabel 2. Laporan Hasil CAT: SKD-CPNS 2018 Formasi Umum (Kelompok 2/Sesi 46) Kementerian Perhubungan

\begin{tabular}{|c|c|c|c|c|}
\hline No. & TWK & TIU & TKP & Total \\
\hline 1. & 75 & 40 & 141 & 256 \\
\hline 2. & 100 & 100 & 126 & 326 \\
\hline 3. & 35 & 40 & 124 & 199 \\
\hline 4. & 80 & 50 & 134 & 264 \\
\hline 5. & 105 & 95 & 138 & 338 \\
\hline 6. & 105 & 85 & 142 & 332 \\
\hline 7. & 60 & 70 & 143 & 273 \\
\hline 8. & 70 & 85 & 131 & 286 \\
\hline 9. & 60 & 95 & 119 & 274 \\
\hline 10. & 60 & 70 & 107 & 237 \\
\hline 11. & 80 & 85 & 137 & 302 \\
\hline 12. & 65 & 40 & 137 & 242 \\
\hline 13. & 45 & 35 & 100 & 180 \\
\hline 14. & 80 & 80 & 121 & 281 \\
\hline 15. & 85 & 55 & 117 & 257 \\
\hline
\end{tabular}

Sumber: BKN

Keterangan: diringkas dari laporan hasil tes SKD, hal 1, Jakarta, 5 November 2018.

Dari laporan hasil CAT: SKD-CPNS 2018 Formasi Umum (Kelompok 2/Sesi 46) Kementerian Perhubungan (tabel 2), diketahui tidak ada peserta yang memenuhi nilai ambang batas kelulusan dalam 1 atau 2 bahkan 3 jenis test yang meliputi TWK, TIU dan TKP (tabel 1). Pada umumnya, mereka tidak memenuhi ambang batas kelulusan dalam TKP.

Sama halnya, dari laporan hasil CAT: SKD-CPNS 2018 Formasi Cumlaude (Kelompok 
2/Sesi 46) Kementerian Perhubungan (lihat tabel 3), diketahui hanya seorang peserta yang memenuhi nilai ambang kelulusan. Hal ini seperti yang terjadi pada formasi umum, mereka tidak lulus dalam 1 atau 2 bahkan 3 jenis test yang meliputi TWK, TIU dan TKP. Pada umumnya, mereka tidak memenuhi ambang batas kelulusan dalam TKP.

Tabel 3. Laporan Hasil CAT: SKD-CPNS 2018 Formasi Cumlaude (Kelompok 2/Sesi 46) Kementerian Perhubungan

\begin{tabular}{|c|c|c|c|c|}
\hline No. & TWK & TIU & TKP & Total \\
\hline 1. & 85 & 55 & 130 & 270 \\
\hline 2. & 105 & 110 & 135 & 350 \\
\hline 3. & 135 & 130 & 142 & 407 \\
\hline 4. & 95 & 110 & 140 & 345 \\
\hline 5. & 125 & 120 & 132 & 377 \\
\hline 6. & 95 & 110 & 145 & 350 \\
\hline 7. & 105 & 85 & 133 & 323 \\
\hline 8. & 65 & 65 & 130 & 260 \\
\hline 9. & 95 & 85 & 113 & 293 \\
\hline
\end{tabular}

Sumber: BKN

Keterangan: diringkas dari laporan hasil tes SKD hal.1, Jakarta, 5 November 2018.

Peserta SKD-CPNS 2018 mengharapkan agar passing grade TKP SKD-CPNS 2018 diturunkan (Tribunnews.com). Menurut peneliti, nilai ambang batas TKP (143) terlalu tinggi, hal ini jauh berbeda bila dibandingkan dengan nilai TWK (75) dan TIU (80) yang lebih rendah. Oleh karena itu, nilai TKP sebaiknya diturunkan. Oleh karena itu, perlu diterapkan prinsip penentuan kelulusan, berdasarkan peringkat terbaik (Lampiran Peraturan MENPANRB No. 36/2018 huruf J Angka 2 huruf d), tidak dibatasi pada formasi khusus melainkan juga pada formasi umum.

Agar memenuhi prinsip keadilan maka penentuan kelulusan berdasarkan peringkat terbaik diterapkan pada formasi umum, dengan melakukan pemeringkatan terhadap nilai ambang batas SKD-CPNS 2018 yaitu nilai kumulatif SKD. Nilai ini tertera pada kolom total dari laporan hasil CAT: SKD-CPNS 2018 (tabel 2). Dengan demikian, maka dapat ditentukan peserta SKD-CPNS 2018 yang lulus. Kelulusan berdasarkan pemeringkatan ini diperuntukkan bagi mereka yang menduduki 3 peringkat teratas saja yang dapat mengikuti Seleksi Kompetensi Bidang (SKB) CPNS Tahun 2018. Dengan demikian prinsip kompetitif dan keadilan dapat terpenuhi (lihat Lampiran Peraturan MENPANRB No. 36/2018 Huruf G angka 3).

Berdasarkan hasil penelitian SKD-CPNS 2018 tersebut di atas, maka dapat ditarik kesimpulan dan saran/rekomendasi sebagai berikut:

1. informasi passing grade SKD-CPNS 2018 yang dinyatakan berdasarkan Peraturan MENPANRB No. 37/2018, tapi isinya ternyata tidak sepenuhnya didasarkan kepada Peraturan MENPANRB, sebagai berikut: (1) Nilai ambang batas SKD adalah nilai minimal yang harus dipenuhi oleh setiap peserta seleksi CPNS bukan melampaui nilai ambang batas; (2) Nilai ambang batas SKD-CPNS 2018 olahragawan berprestasi tidak ditentukan dalam informasi passing-grade SKD-CPNS 2018, seharusnya ditentukan, nilai terendah dari peserta seleksi CPNS Olahragawan Berprestasi Internasional merupakan nilai ambang batas hasil SKD; (3) Nilai TIU formasi dokter spesialis \& instruktur 
penerbang yang dituntut bekerja dengan standar error sangat minimal disamakan dengan jalur umum yaitu 80 akan tetapi dibawah jalur cumlaude dan diaspora yang ditentukan paling sedikit 85 .

2. Kelulusan peserta tahap SKD-CPNS 2018 secara nasional sangat kecil hanya mencapai $3 \%$.

Temuan menunjukkan bahwa peserta secara umum tidak mencapai skor minimum TKP = 143 yang terlalu tinggi karena mereka sangat sulit mencapainya, berbeda dengan nilai $\mathrm{TWK}=75$ dan TIU $=80$ yang rendah, sebagian dari peserta dapat mencapainya.

Saran/rekomendasi berdasarkan kesimpulan tersebut di atas, maka perlu meninjau ulang informasi passing grade SKD-CPNS 2018 agar sesuai dengan Peraturan MENPANRB No. 37/ 2018. Nilai ambang batas TKP (143) terlalu tinggi, hal ini jauh berbeda bila dibandingkan dengan nilai TWK (75) dan TIU (80) yang lebih rendah. Oleh karena itu, nilai TKP sebaiknya diturunkan. Di samping itu, perlu diterapkan penentuan kelulusan berdasarkan peringkat terbaik, tidak hanya pada formasi khusus melainkan juga formasi umum, dengan melakukan pemeringkatan terhadap nilai ambang batas SKD-CPNS 2018 yaitu nilai kumulatif (total) SKD agar memenuhi prinsip keadilan.

\section{REFERENSI}

Badan Kepegawaian Negara, Laporan Hasil CAT: SKD-CPNS 2018 Formasi Cumlaude (Kelompok 2/Sesi 46) Kementerian Perhubungan, Jakarta, 5 November 2018, hal. 1;

Badan Kepegawaian Negara, Laporan Hasil CAT: SKD-CPNS 2018 Formasi Umum (Kelompok 2/Sesi 46) Kementerian Perhubungan, Jakarta, 5 November 2018, hal. 1;

Detik.com (10 November 2018). BKN: Peserta yang Lulus Tes CPNS Baru 3\%. https://finance.detik.com/lowongan-kerja/d-4295955/;

Kementerian Pendayagunaan Aparatur Negara dan Reformasi Birokrasi, Passing Grade Seleksi Kompetensi Dasar CPNS 2018;

Kompas.com (7 November 2018), Gubernur Maluku Kecewa Peserta Tes CPNS Tahap Pertama yang lolos hanya 8 orang. https://regional. Kompas.com/read/2018/11/ 07/ 08173493/;

Liputan6.com (31 Juli 2019). BKN Ungkap Kendala Pendaftaran CPNS 2018. https://www.liputan6.com/bisnis/read/4025960/bkn-ungkap-kendala-pendaftaran-cpns2018;

Peraturan Pemerintah Nomor 11 Tahun 2017 tentang Manajemen Pegawai Negeri Sipil;

Peraturan Menteri Pendayagunaan Aparatur Negara dan Reformasi Birokrasi Nomor 36 Tahun 2018 Tentang Kriteria Kebutuhan PNS dan Pelaksanaan Seleksi CPNS Tahun 2018;

Peraturan Menteri Pendayagunaan Aparatur Negara dan Reformasi Birokrasi Nomor 37 Tahun 2018 Tentang Ambang Batas Seleksi Kompetensi Dasar Pengadaan CPNS Tahun 2018;

Sedarmayanti (2013). Reformasi Administrasi Publik, Reformasi Birokrasi, dan Kepemimpinan Masa Depan, Bandung: PT Refika Aditama;

Tribunnews.com (12 November 2018). Jawaban BKN Saat Diminta Warganet Turunkan Passing Grade CPNS 2018. www.tribunnews.com/section/2018/11/12/ 